\title{
Barriers to the Implementation of the Nursing Approach in Public Hospitals in Lubumbashi in the Democratic Republic of Congo: A Cross-Sectional Descriptive Study
}

\author{
Ndayi Kabamba Julie1, Ilunga Kandolo Simon ${ }^{*}$, Kabange Umba Irène1,

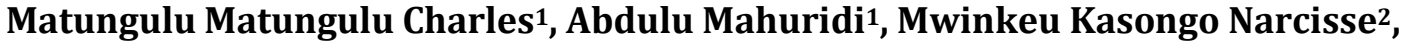 \\ Malonga Kaj Françoise ${ }^{1}$ \\ ${ }^{1}$ Ecole de Snté Publique de L’Universite de Lubumbashi, Lubumbashi, Democratic Republic of Congo \\ ${ }^{2}$ Institut supérieur des Techniques Médicale de Lubumbashi, Lubumbashi, Democratic Republic of Congo \\ Email: *silungak@gmail.com
}

How to cite this paper: Julie, N.K., Simon, I.K., Irène, K.U., Charles, M.M., Mahuridi, A., Narcisse, M.K. and Françoise, M.K. (2017) Barriers to the Implementation of the Nursing Approach in Public Hospitals in Lubumbashi in the Democratic Republic of Congo: A Cross-Sectional Descriptive Study. Open Access Library Journal, 4: e3721. https://doi.org/10.4236/oalib.1103721

Received: June 8, 2017

Accepted: July 8, 2017

Published: July 11, 2017

Copyright $\odot 2017$ by authors and Open Access Library Inc.

This work is licensed under the Creative Commons Attribution International License (CC BY 4.0).

http://creativecommons.org/licenses/by/4.0/

\begin{abstract}
Introduction: The nursing approach (NA) is the essence of the nursing profession. However, its implementation is almost absent in the hospitals of the Democratic Republic of Congo (DRC). Objectives: The aim of this study was to determine nurses' knowledge, attitudes and practices in relation to the nursing approach and to identify barriers to the implementation of this approach. Methods: To achieve these objectives, we carried out a cross-sectional descriptive study among the nurses of the 11 public hospitals of Lubumbashi, from June to September 2015. Thanks to a validated questionnaire, we collected the data by interview, supported by participatory observation. Results: The results showed that $67.6 \%$ of respondents were trained on NA; However, $99.3 \%$ did not know the exact number of NA steps and $62.6 \%$ did not cite any steps; The majority (93.5\%) of trainees on NA find that this process provides quality patient care; $100 \%$ of the sample wish to put it into practice; $100 \%$ of the sample need continuous training on NA including $67.6 \%$ to improve knowledge and $32.4 \%$ to learn; $89.1 \%$ of those trained reported not practicing NA, but participating direct observation gave $100 \%$ of non-practice. The barriers to implementation of the NA were inadequate nursing staff (75.6\%), inadequate equipment (71.5\%), lack of time (62.6\%), lack of theoretical and practical knowledge (47.2\%), lack of nursing records (26\%) and lack of institution for nursing care within the hospital (17\%). Conclusion: Therefore, capacity building of nurses through continuing education, as well as initial training on NA, would increase their knowledge, reinforce positive attitude and promote its implementation, all supported by improved working condi-
\end{abstract}


tions and the implementation of a professional nursing quality assurance organization.

\section{Subject Areas}

Nursing

\section{Keywords}

Nursing Care, Barriers, Implementation, Public hospitals, Lubumbashi

\section{Barriers to the implementation of the nursing approach in public hospit- als in Lubumbashi in the Democratic Republic of Congo: a cross-sectional descriptive study}

The nursing approach is the essence of the nursing profession. It is a process of adapting a care as prescribed by the physician as prescribed by the nurse and the overall care strategy for a person [1].

The nursing process is used in clinical practice worldwide to provide patients with quality individualized care, and the lack of its application can reduce the quality of care [2].

Manal Hamed Mahmoud et al., in Egypt found that the majority of nurses (94.6\%) indicated that they had good knowledge of the nursing approach. Data collection is difficult for the majority (63.5\%), and nurses say that having theoretical and practical knowledge (96\%) facilitates the implementation of the nursing approach [2].

In Ethiopia, in a study to analyze the practice of nursing, Fisseho Hagos et al. found that the majority of nurses (90\%) had little knowledge of the nursing approach and $99.5 \%$ had a positive attitude towards this process. All respondents say they do not practice the nursing process because of inadequate nursing staff (75\%); slightly over half of nurses reported that there were time constraints to apply the nursing process; $43 \%$ said the nursing process is a waste of time; $81.5 \%$ indicated they were willing to apply the nursing process; approximately $88 \%$ of nurses said that the nursing process provides quality nursing care [3].

In addition, Joel Adeleke Afolayan et al. in Nigeria, in their study to evaluate the use of the nursing approach, found that while nurses had a good theoretical knowledge of the nursing process, they did not practice it in the care of their patients because of inadequate working knowledge, inadequate nursing staff, overworking, inadequate work equipment [4].

As for Brou Ahonzi, in Côte d'Ivoire, 100\% of nurses in her sample do not use the nursing approach due to the lack of institutionalization of this process within the hospital (88\%), lack of reinforcement (40\%), the fact that the care approach is too thought-provoking (20\%) and the lack of equipment (100\%) [5].

Zewdu Shewangizaw et al., Ethiopia, in their study on the determinants of the implementation of the nursing process found that $32.7 \%$ of nurses have implemented the nursing process while $67.3 \%$ have not implemented the nursing 
process [6].

Mbithi Denis Ngao, in Kenya found that $81.3 \%$ had received continuing education on the nursing approach; $33.1 \%$ applied the nursing approach, only $8.2 \%$ correctly cited all stages of the nursing process [7].

In Nigeria, Kollie Erhuvwukorotu Siemuri et al., reported that the use of the nursing process was unsatisfactory in some parts of Africa and was influenced by personal, professional and institutional factors. Their study showed that personal factors emanating from nurses specific to the nursing knowledge about the nursing process is not significant $R^{2}=0.012, P=0.447$. Occupational factors have a strong correlation with the use of the nursing process $R^{2}=0.404, P=$ 0.000 , and institutional factors have shown a strong correlation with the use of nursing process $R^{2}=0.410, P=0.000$ [8].

Another study in Ethiopia showed that the knowledge factor has the highest predictive value of 0.350 in institutional use $(0.222)$ and occupational factor $(0.063)$ and least influential is the attitude factor (0.019). This result shows that the knowledge factor has the most important influence on the use of the nursing process [9].

Akbari M. et al., found that the biggest individual barrier for nurses was the lack of information about the concept process of nursing (79.4\%) and inadequate learning about the nursing process in the units of care (71.4\%). The most important barriers are the lack of sufficient time to do the nursing process due to the excessive number of patients (84.1\%), lack of support for the implementation of the nursing process $(76.2 \%)$ and the submission of non-nursing tasks to nurses (76. 2\%) [10].

Aiyedun, JIChukwu et al. in Abuja, to examine the perception of the implementation of the nursing process, found that $45 \%$ of nurses indicated that the shortage of the workforce is a major challenge for the implementation of the nursing process, $33 \%$ agreed that the nurses' poor attitude towards documentation is a major barrier, while $22 \%$ said that there are time constraints. The result also revealed that there is a significant relationship between years of practice and use of the nursing process. In addition, $83 \%$ of nurses argued that implementation of the nursing process will reduce mortality and morbidity rates, and $69 \%$ of nurses believe that quality nursing care can not be achieved without the nursing process [11]. Up to now, no study has been published on the nursing approach either locally (in Lubumbashi), regional (Haut-Katanga) or national (DR Congo).

\section{Objectives}

The overall objective of our study is to contribute to the improvement of knowledge.

Nurses on the nursing approach and the complete well-being of the patients in the HGR of the city of Lubumbashi.

Specifically, our objectives are to:

1) Determine the knowledge, attitudes and practices of nurses from the Lubumbashi HGRs on the nursing approach,

2) Identify the barriers to the practice of nursing care by the nurses of the 
HGRs of the city of Lubumbashi.

\section{Methodology}

Our study was carried out in the Democratic Republic of the Congo, in the province of Upper Katanga (one of the four provinces from the cutting of the former province of Katanga) in the city of Lubumbashi.

We conducted a cross-sectional descriptive study among nurses from June to September 2015.

\section{Population and sample}

Our sample size was 204 nurses out of a total of 328 who constitute the nursing unit of 11 hospitals in the city of Lubumbashi. The sampling was exhaustive.

Sampling technique

We proceeded by stratum sampling. The 11 primary hospitals were the primary hospitals (Jason SENDWE Hospital, Lubumbashi University Clinic, GHR Kisanga, Katuba, Kenya, Vangu, SNCC, Hakika, Kamalondo, Gecamine Sud Hospital and the Rwashi Military Hospital). Their choice was motivated by their status as hospitals in the health system. The units of care (internal medicine, surgery, pediatrics and gynecological obstetrics) were selected and considered as secondary strata, and here the exhaustiveness of the nurses was questioned. A census of the nurses working in these care units made it possible to control the total workforce.

Inclusion criteria: Are included in our study, Nurses working at the places chosen for the study; Nurses willing to participate voluntarily after explanation for informed consent; Nurses present in the department during the period of data collection. Exclusion Criteria Nurses not working in the hospitals and units of care involved in the study; Nurses did not agree to participate in the study; Nurses absent or on leave at the time of the investigation; Interns and/or development nurses. Collection of data after receiving the agreement and the research attestation from the management team, we met with the medical directors and the nursing directors (head nurses of the hospitals concerned by the study for a contact and Explanation on the work to request authorization to enter the care units. After obtaining the written agreement (signature) of the hospital directors and the verbal of the nursing directors, we went down for the data collection was done by interviewers who were trained prior to field descent on the survey procedure, study objectives, confidentiality, Anonymity and the informed consent of the respondents, as well as the understanding of the questionnaires. Before the field trip the investigators made a simulation of the survey to study its real situation. This allowed us to verify: a good understanding of the role of each, an understanding of the survey procedure, the procedure for selecting study participants, and allowed us to become familiar with the issues, and it is a mechanism to minimize biases during data collection. We used 3 instruments for the collection of quantitative and qualitative data. For the quantitative method, the questionnaire and the participating direct observation were used. The questionnaire included sociodemographic data from nurses, knowledge of the nursing ap- 
proach, nurses' attitude to the nursing approach, implementation of the nursing approach, and factors that prevented the Implementation of the nursing approach. The Compliance Guide was developed for data that may or may not confirm the implementation of the nursing approach (observation of the implementation of the five steps of the nursing process) and the literature review allowed us to verify the existence of the nursing file and the preparation of the report.

\section{Data analysis}

The data were encoded and analyzed using the Epi Info 7.1.1.1 and SPSS 20.0 software. The variables were summarized through frequency tables and graphs.

\section{Validity of data collection instrument}

The management team read it and the remarks were corrected before the pre-survey and the data collection itself.

Internal validity: This study has great potential for internal validity due to the use of different data collection tools. The set of different information gathered by questionnaire from the nurses, observation of the work of the nurses on the five steps the nursing approach and the documents used by nurses, reduces the distortions in the measurements and thus gives satisfactory internal validity.

External validity: Our instruments have been pre-tested with nurses. 20 nurses or $1 / 10^{\text {th }}$ of the sample. These people are not part of our study.

Ethical Considerations

To protect the rights and freedoms of the participants in our study, we respected anonymity (no names of participants were mentioned on the questionnaires); Confidentiality (no participant knows the other's answers), we asked for a raid authorization beforehand to collect the data from our supervisors, after we had replied, we took with us the questionnaires); We explained to each participant the objectives of the study to obtain their informed consent. The investigation thus proceeded with strict respect for human rights. The protocol of the study was submitted to the ethics committee of the University of Lubumbashi and we defended it, and regarding the sharing of benefits, we will give the hospitals that participated in the study the results of the study. And the environment will not be affected.

\section{Pilot study}

A pre-test was conducted with 20 nurses in a hospital that will not be part of the nursing study.

\section{Study variables}

Our study includes the following variables: socio-demographic variables, variables related to nursing process knowledge, variables related to the attitude of nurses to the nursing approach, variables related to the practice of the nursing and variable care approach in relation to the factors preventing the practice of the nursing approach

\section{Results}

The results showed that $77 \%$ of the respondents were women and $23 \%$ were 
men, giving a sex ratio of one man to three women (Figure 1). The average age of nurses was $47.7 \pm 10.5$ years (minimum: 15 years, maximum: 65 years); The age group 45 - 54 was the majority (37.7\%) followed by the age group $35-44$ (23.5\%) (Figure 2). As for the level of study, $50 \%$ of respondents were graduates (A1), followed by $25 \%$ secondary (A2) and only $9 \%$ of graduates (Figure 3 ). We noted that $30.5 \%$ of nurses had 10 to 19 years of professional experience (Figure 4).

As for nurses' knowledge of the nursing approach (Table 1), we observed that $67.6 \%$ of nurses were trained in the nursing approach, of which $87 \%$ received nursing training and $13 \%$ in continuing education. Of those trained in the nursing approach, $0.7 \%$ knew the exact number (5 steps), $92 \%$ of which cited the implementation of interventions or care delivery (the majority of them Confusion with the 3 stages of a nursing technique: preparation, execution,

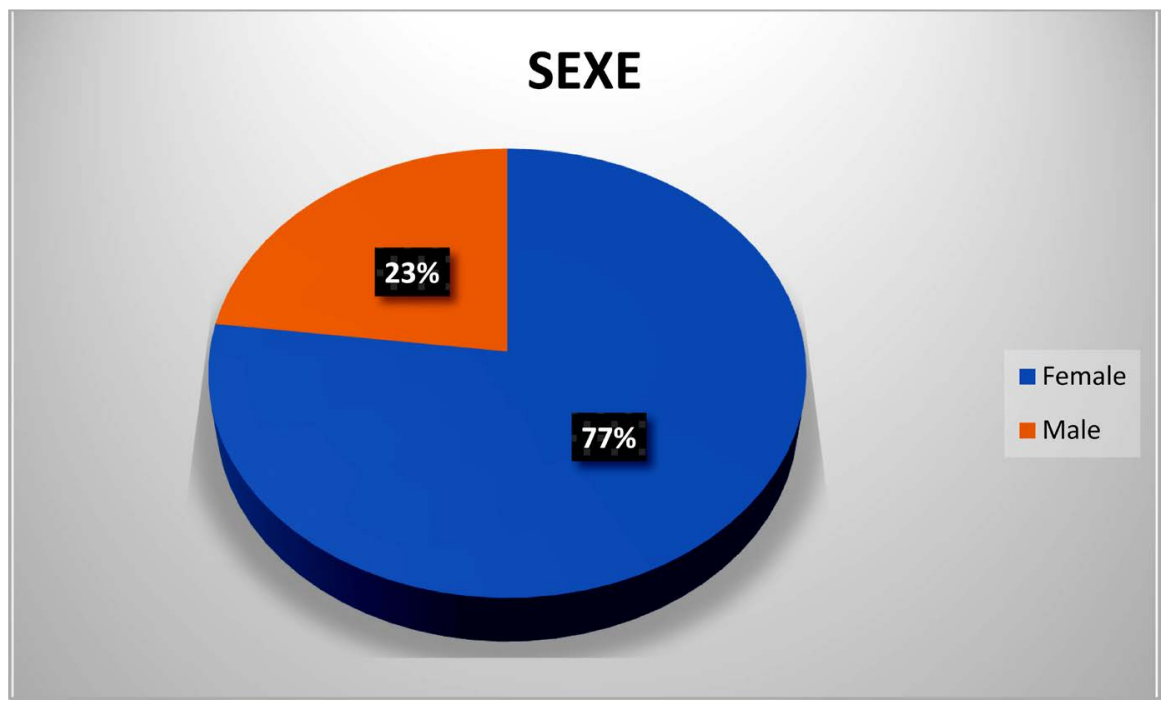

Figure 1. Nurse sex.

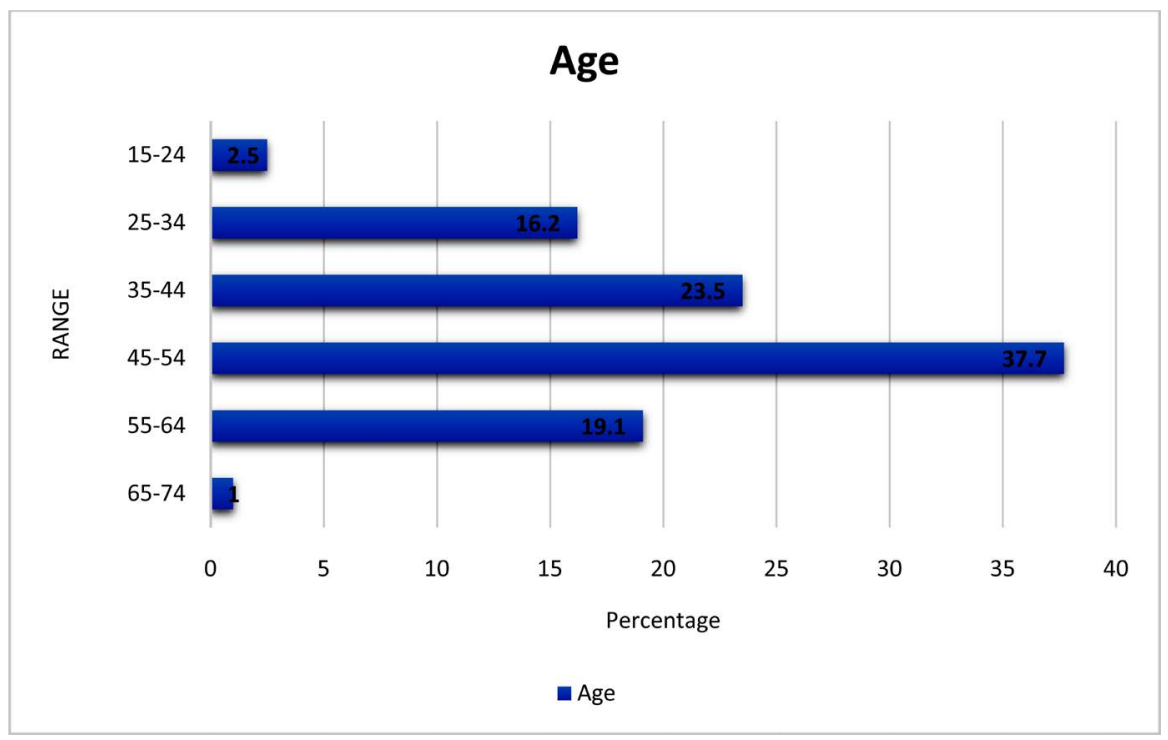

Figure 2. Age range. 


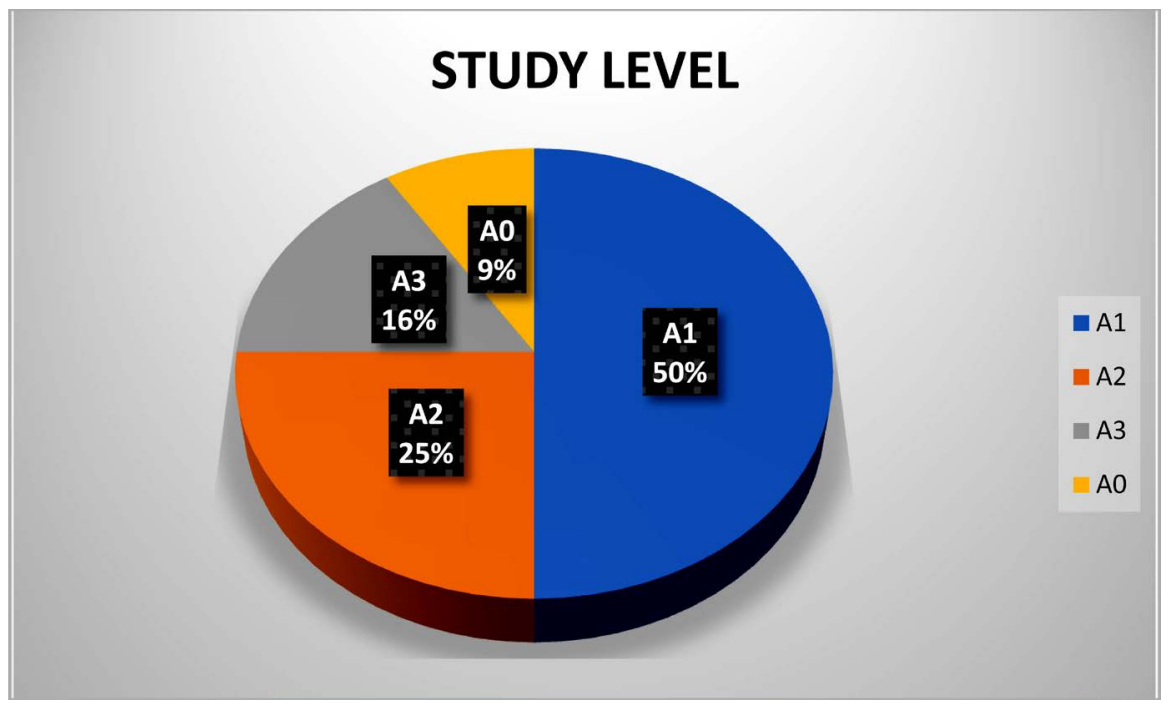

A1: Nurse with a under graduate level; A2: Nurse with a secondary level; A3: Nurse with a two years secondary level; A0: Nurse with a graduate level.

Figure 3. Study level.

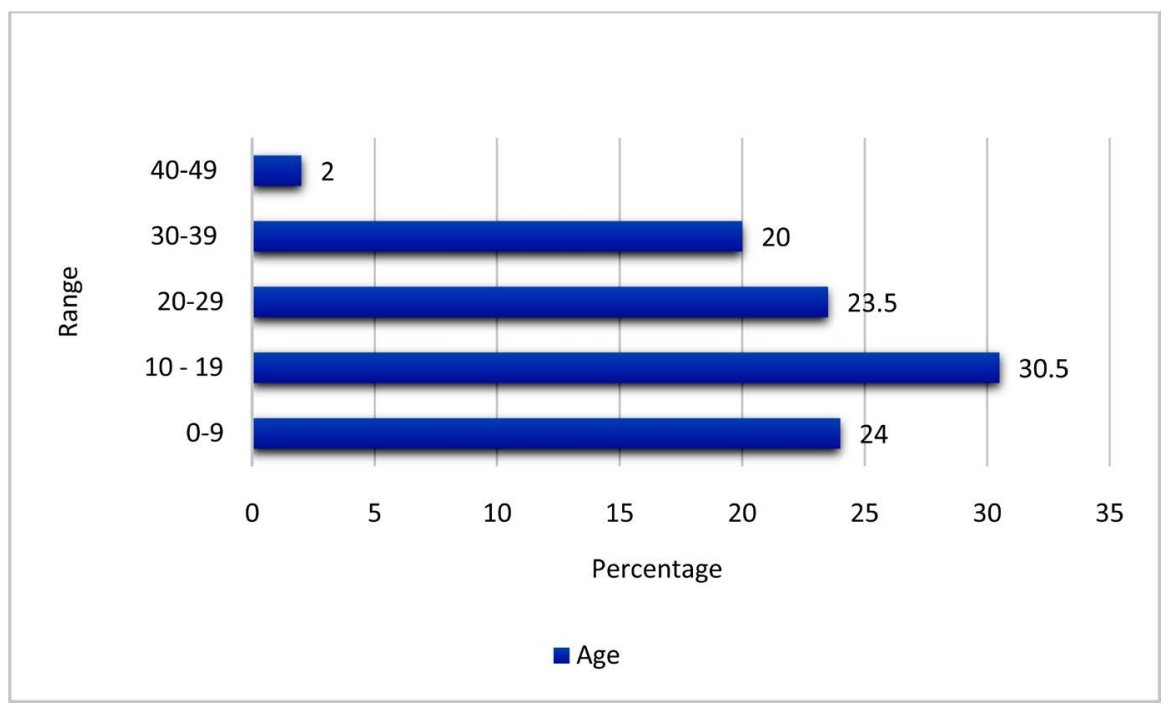

Figure 4. Seniority as a nurse.

reordering); $24 \%$ cited data collection and $0.7 \%$ or a nurse cited assessment of care, and it was the only nurse who cited the five steps of the nursing approach; $99.3 \%$ do not know the exact number; $71.7 \%$ of those trained in the nursing approach claim to know its usefulness and $62.6 \%$ of those who claimed to know the usefulness of the nursing approach cited no use (do not know), and $29.3 \%$ gave "evaluating the problems of the patients" as a useful tool.

The results showed that $93.5 \%$ of those who had received training in nursing practice found that this process was able to provide patients with quality care; $100 \%$ need training on ISD, of which $67.6 \%$ of the sample need this training to improve knowledge about ISD and $32.4 \%$ to learn it and $100 \%$ of respondents wish to practice it (Table 2).

In terms of nursing practice (Table 3 ), it is clear from our observations that 
$89.1 \%$ of those who received training in nursing practice do not practice the nursing approach and $10.9 \%$ claim to put it into practice; The most cited reason is the inadequacy of the nursing staff with $75.6 \%$, followed by the inadequacy of the equipment with $71.5 \%$, the lack of time with $62.6 \%$, the lack of theoretical and practical knowledge with $47.2 \%$.

The results showed that $93.5 \%$ of those who had received training in nursing practice found that this process was able to provide patients with quality care; $100 \%$ need training on ISD, of which $67.6 \%$ of the sample need this training to improve knowledge about ISD and $32.4 \%$ to learn it and $100 \%$ of respondents wish to practice it (Table 2).

Table 1. Nurses' knowledge of the nursing approach.

\begin{tabular}{|c|c|c|}
\hline Variables & Frequencies & Percentage \\
\hline \multicolumn{3}{|l|}{ Training received $(n=204)$} \\
\hline Yes 13867.6 & 138 & 67.6 \\
\hline No & 66 & 32.4 \\
\hline \multicolumn{3}{|l|}{ Circumstances in which training was received $(n=138)$} \\
\hline $\begin{array}{l}\text { During the recycling (Continuous training) on the } \\
\text { nursing approach (NA) }\end{array}$ & 18 & 13 \\
\hline At school (Initial training) & 120 & 87 \\
\hline \multicolumn{3}{|l|}{ Number of steps in the nursing approach (NA) } \\
\hline Does not know & 39 & 28.3 \\
\hline 2 steps & 4 & 2.9 \\
\hline 3 steps & 88 & 63.8 \\
\hline 4 steps & 6 & 4.3 \\
\hline 5 steps & 1 & 0.7 \\
\hline \multicolumn{3}{|l|}{ Stage Names of the nursing approach (NA) } \\
\hline Data collection & 33 & 24 \\
\hline Analysis and interpretation of data & 7 & 5 \\
\hline Care planning & 5 & 3,6 \\
\hline Implementation of interventions (Implementation) & 127 & 92 \\
\hline Evaluation of care & 1 & 0.7 \\
\hline \multicolumn{3}{|l|}{ Know the usefulness of nursing approach (NA) } \\
\hline Yes & 99 & 71.7 \\
\hline No & 39 & 28.3 \\
\hline \multicolumn{3}{|l|}{ The usefulness of nursing approach (NA) $(n=99)$} \\
\hline Individualizing care & 10 & 10.1 \\
\hline Evaluating the problems of patients & 29 & 29.3 \\
\hline Empowering nurses & 7 & 7.1 \\
\hline Ensuring continuity of care & 7 & 7.1 \\
\hline Improving the quality of patient care & 9 & 9.1 \\
\hline Do not know 6262.6 & 62 & 62.6 \\
\hline
\end{tabular}


Table 2. Attitudes of nurses on the nursing approach.

\begin{tabular}{ccc}
\hline Variable & Frequency & Percent \\
\hline Nursing approach (NA) provides quality care $(n=138)$ & 129 & 93.5 \\
Yes & 9 & 6.5 \\
Do not know & & \\
Wishing to practice nursing approach (NA) $(n=204)$ & 204 & 100 \\
Yes & 0 & 0 \\
No & & 100 \\
Yes & 204 & 0 \\
No & 0 & 67.6 \\
Need for nursing approach (NA) training & 138 & 32.4 \\
\hline Improving knowledge on nursing approach (NA) & 66 & \\
Learning nursing approach (NA) & &
\end{tabular}

Table 3. Practice of nurses in the nursing process.

\begin{tabular}{ccc}
\hline Variable & Frequency & Percent \\
\hline Pes & 15 & 10.9 \\
No & 123 & 89.1 \\
Reasticing nursing approach (NA) $(n=138)$ & & \\
Lack of time & 58 & 47.2 \\
Insufficient equipment & 9 & 7.3 \\
Insufficient nursing staff & 77 & 62.6 \\
Never seen a nurse put this process into practice & 88 & 71.5 \\
Lack of nursing records in the hospital & 93 & 75.6 \\
Lack of institution of this process within the hospital & 21 & 17 \\
Lack & 32 & 26 \\
\hline
\end{tabular}

Referring to practice in nursing (Table 3), it is clear from our questionnaire that $89.1 \%$ of those who received training in nursing practice do not practice the nursing approach and $10.9 \%$ claim to put it into practice. Speaking of barriers, the most cited reason is the inadequacy of the nursing staff with $75.6 \%$, followed by inadequate equipment with $71.5 \%$, lack of time with $62.6 \%$, lack of theoretical knowledge and practices with $47.2 \%$.

\section{Discussion}

\section{Socio-demographic characteristics}

The majority of our sample, $77 \%$ are women; This feminine preponderance confirms the feminization of the nursing profession since its inception.

Knowledge of the nursing approach 
In our study, $67.6 \%$ of nurses were trained in nursing care, our results are lower than those of Mbithi Denis Ngao in Kenya who found that $81.3 \%$ had received continuing education on the approach of nursing [7]. This inferiority of our results could be explained by the absence of a national and local policy, of continuous training of nurses on the approach of nursing, notwithstanding the presence of the multiple partners of government in health.

As for the stages, $0.7 \%$ of our respondents trained correctly the five steps. These results are lower than Mbithi Denis Ngao, in Kenya who found that $8.2 \%$ correctly cited all stages of the nursing approach [7]. We also found that $71.7 \%$ claim to know its usefulness, but $62.6 \%$ of them did not cite any utility. These two observations, (not knowing how to cite the steps of the approach of care Nurses and not knowing its usefulness) prove that nurses in our sample, although trained, lack knowledge about the nursing approach.

This could be explained by the glaring absence of a system of in-service training to effectively manage on-the-job training activities. There is also evidence of inadequate training in relation to the health care needs of the population. This could be partly explained by the use of inadequate training programs, the organizational framework for the delivery of courses that did not meet standards, the lack of suitable training places, the qualitative and quantitative inadequacy of teachers, Lack of model schools for retraining and testing of training programs, etc. [12].

This is contrary to Manal Hamed Mahmoud et al. in Egypt, who found that the majority of nurses (94.6\%) have good knowledge of the nursing approach [2], Joel Adeleke Afolayan et al. in Nigeria, who found that nurses had a good theoretical knowledge of the nursing process [4], by Fisseho Hagos et al. in 2014, who found that $90 \%$ had little knowledge about the nursing approach [3]. While $47.2 \%$ of our respondents lack the theoretical and practical knowledge of the nursing approach, Manal Hamed Mahmoud et al. in 2014 have found that $96 \%$ of nurses say that having theoretical and practical knowledge facilitates the execution of the nursing approach [2].

Nurses' attitude to the nursing approach compared to our study, $93.5 \%$ of respondents said that this process provides quality care to patients. Our results are superior to those of Fisseho Hagos et al. in 2014, who found that $88 \%$ of nurses said that the nursing process provides quality nursing care [3] in Aiyedun, JI Chukwu, et al. in Abuja, who found that $69 \%$ of nurses felt that quality nursing care cannot be achieved without the care process [11].

In addition, in our study $100 \%$ of nurses want to put it into practice. Our results are superior to those of Fisseho Hagos et al. who found that $81.5 \%$ indicated they were ready to apply the nursing process [3].

In addition, our study shows that $100 \%$ of nurses expressed the need for continuing education on the nursing approach, of which $67.6 \%$ wanted to improve knowledge of the process and $32.4 \%$ wanted to learn it. This confirms that nurses have no knowledge. The trained have lost everything by working in routine, but at least their attitude is positive about the nursing approach. These re- 
sults are similar to those of Fisseho Hagos et al., who found that $99.5 \%$ had a positive attitude towards this process [3].

\section{Convenient}

In our study, participating active observation showed that $100 \%$ of nurses do not practice the nursing approach, although the questionnaire showed that $10.9 \%$ put it into practice. Our results are similar to those of Fisseho Hagos et al., who found that all respondents say they do not practice the nursing process [3] in Brou Ahonzi, in Côte d'Ivoire, who showed That $100 \%$ of nurses in her sample did not use the nursing approach [5] and Joel Adeleke Afolayan et al. in Nigeria, who found that although nurses had a good theoretical knowledge of the nursing process, they did not Did not practice it in the care of their patients [4] but superior to Zewdu Shewangizaw et al. in Ethiopia, who found that $67.3 \%$ did not implement the nursing process [6], and to Mbithi Denis Ngao in Kenya who found that $33.1 \%$ were practicing nursing, by inference, we estimate that $66.9 \%$ did not practice it [7].

\section{Obstacles (factors preventing) the practice of the nursing approach}

Our study proved in decreasing order that the inadequacy of the nursing staff is the major obstacle with 75. 6\%. The Ministry of Public Health (RDC) in 2010 also showed that the unattractive nature of paid wages creates instability in the staff, which is thus in a continuous search of the highest bidder. The internal and external migration of health personnel thus becomes a significant threat [12].

Our results are similar to those of Fisseho Hagos et al., who found that $75 \%$ of nurses do not practice the nursing process because of inadequate nursing [3]; but superior to those of Aiyedun, JIChukwu, et al. in Abuja, who found that $45 \%$ of nurses indicated that labor shortage is a major challenge for the implementation of the nursing process [11] and below those of Joel Adeleke Afolayan et al. in Nigeria who found that nurses did not practice it in the care of their patients because of inadequate nursing staff.

Inadequate equipment ranked second with $71.5 \%$. Our results are lower than those of Brou Ahonzi, in Côte d'Ivoire who found that $100 \%$ of nurses in his sample Do not use the nursing approach because of inadequate material, [5] and Joel Adeleke Afolayan et al. in Nigeria found that nurses did not practice it in the care of their patients because of Insufficient work equipment [4]. Thus, making available work materials could promote the implementation of the nursing approach.

Third, comes lack of time with $62.6 \%$; this result is superior to those of Fisseho Hagos et al., who found that half of nurses indicated that there were time constraints in applying the nursing process [3]; Aiyedun, JIChukwu, et al. in Abuja [11] found that $22 \%$ of nurses reported time constraints, and Joel Adeleke Afolayan et al. in Nigeria found that although Nurses had a good theoretical knowledge of the nursing process, they did not practice it in the care of their patients because of the work overload [4], and in the end Akbari M. et al. in 2011, found that nurses did not put in practice the nursing approach because of the lack of sufficient time to do the nursing process because of the excessive number 
of patients (84.1\%) [10]. Discharging the nurses would offer them a little more time to think about the supply of care by following the approach of the care of which they are authors.

Fourth, the lack of theoretical and practical knowledge about the nursing approach with 47.2\%; These results are superior to those of Brou Ahonzi in Côte d'Ivoire who found that $40 \%$ of nurses in his sample did not use the nursing approach due to a lack of capacity building on the care approach [5], Lower than those of Akbari M. et al. in 2011, who found the lack of information about the concept of care process at 79.4\% [10]; But Joel Adeleke Afolayan et al. in Nigeria found that nurses did not put it into practice in the provision of care to their patients because of insufficient working knowledge [4]. It is here the necessity and imperative to better train the nurses on the approach of the nurses in order to see them one day implement it optimally.

Fifth, the lack of institutional process within hospitals to $17 \%$. These results are much lower than Brou Ahonzi in Côte d'Ivoire who found that $88 \%$ of nurses in his sample did not use the nursing approach due to the lack of institution of this process within the hospital [5], And Akbari M. et al., who found $76.2 \%$ of respondents who cited lack of support for implementation of the nursing process [10]. This demonstrates the necessity of the leaders who could federate the whole to the adoption of this process as mandatory mode of offer of the care of the sick.

Sixth, the lack of nursing record at $26 \%$. This could be explained by the lack of a law governing the nursing profession until the collection of our data. The texts governing the health sector are obsolete. As the health sector framework law was not adopted, the latter (health sector) continues to be governed by the 1952 decree on the art of healing in Rwanda, Urundi and Congo Kinshasa, An independent Congolese state [12].

\section{Conclusions}

Dedicated to the nursing approach in Lubumbashi hospitals, it aimed at two objectives: to determine nurses' knowledge, attitudes and practices regarding the nursing approach and to identify barriers to the implementation of this approach. To achieve these objectives, we carried out a cross-sectional descriptive study among nurses in the Lubumbashi hospitals from June to September 2015. Using a validated questionnaire, we collected the data by interview, supported by participatory observation.

The results showed that $67.6 \%$ of respondents reported that they had already received training in nursing care; however, $99.3 \%$ did not know the exact number of steps in the process; $71.7 \%$ claim to know the usefulness of the nursing approach, but $62.6 \%$ of them did not mention any step. The majority (93.5\%) of the CIS trainees find this process to provide quality care to patients; $100 \%$ of the sample wish to put it into practice; $100 \%$ of the sample need continuous training on ISD including: $67.6 \%$ to improve knowledge and $32.4 \%$ to learn. Hence, the nurses in our study have a positive attitude towards the nursing approach; $89.1 \%$ 
of the trainees do not practice it according to the questionnaire data, but the direct participant observation gives $100 \%$ of non-implementation. The barriers to implementation of the nursing approach were inadequate nursing staff $(75.6 \%)$, inadequate equipment (71.5\%), lack of time (62.6\%), lack of theoretical and practical knowledge (47.2\%), lack of nursing record (26\%), lack of institution of nursing procedure within the hospital (17\%), never seen a nurse put into practice the nursing approach (7.3\%).

Therefore, capacity building of nurses through continuing education, as well as initial training in the nursing approach, would increase their knowledge and promote its implementation, supported by the improvement of working conditions and the implementation of work of a professional nursing quality assurance organization for the sake of patients and communities.

\section{Conflicts of Interest}

None.

\section{References}

[1] Psiuk, T. (2006) La démarche clinique: évolution de la singularité vers l'interdisciplinarité. In Recherche en soins infirmiers, 84, 20.

[2] Manal, H.M. and Hala, M.B. (2014) Barriers and Facilitators for Execution of Nursing Process from Nurses' Perspective. International Journal of Advanced Research, 2, 300-315.

[3] Fisseha, H., Fessehaye, A., Fikadu, B., Semarya, B. and Alemseged, A. (2014) Application of Nursing Process and Its Affecting Factors among Nurses Working in Makelle Zone Hospital, Northen Ehtiopia. Nursing Research and Practice, 2014, 1-8. http://dx.doi.org/10.1155/2014/675212

[4] Afolayan, J.A., Donald, B., Baldwin, D.M., Onasoga, O. and Babafemi, A. (2013) Evaluation of the Utilization of Nursing Process and Patient Outome in Psychiatric Nursing: Case Study of Psychiatric Hospital Rumuigbo, Port Harcourt. Advances in Applied Science Research, 4, 34-43.

[5] Ahonzi, Br. (2007) Mise en place du dossier infirmier dans les services de santé en côte d'Ivoire.

http://www.memoireonline,.com/04/10/3280/m-Mise-en-place-du-dossier-infirmie r-dans-les-servi..lu\%20le\%2013/08/2013

[6] Zewdu, S. (2015) Determinants towards Implementation of Nursing Process. American Journal of Nursing Science, 4, 45-49.

https://doi.org/10.11648/j.ajns.20150403.11

[7] Mbithi, D.N. (2015) Assessing Barriers to Implementation of Nursing Process among Nurses Working at Machakos Level 5 Hospital. Thèse.

http://erepository.uonbi.ac.ke:8080/bitstream/handle/11295/94027/Ngao_Assessing \%20Barriers\%20To\%20Implementation\%200f\%20Nursing\%20Process\%20Among \%20Nurses\%20Working\%20At\%20Machakos\%20Level\%205\%20Hospital.pdf?seque nce=4\&isAllowed $=y$ lu le 09/12/2016

[8] Erhuvwukoroti, H.S., Foluso, O.O. and Chimonso, N.U. (2014) Factors Influencing the Utilization of the Nursing Process. International Journal of General Medecine and Pharmacy, 3, 57-64,

[9] Adeyemo, F.O. and Olaogun, A.A. (2013) Factors Affecting the Use of Nursing 
Process in Health Institutions in Ogbomoso Town, Oyo State. International Journal of Medicine and Pharmaceutical Sciences (IJMPS), 3, 91-98.

[10] Akbari, M. and Shamsi, A. (2011) A Survery on Nursing Process Barriers from the Nurses' View of Intensive Care Units. Iranian Journal of Critical Care Nursing, 4, 181-186.

[11] Aiyedum, J. and Chukwu, I. (2014) Evaluation of the Challenges of Nursing Process Practice at the University of Abuja Teaching Hospital. International Journal of Medical Health Science Research, 2, 93-100.

[12] Ministère de la santé, secrétariat général à la santé et programme national d'approvisionnement en médicament, cartographie des systèmes d'approvisionnement et de distribution des médicaments et autres produits de santé en RDC, 2010, Kinshasa RD Congo.

http://apps.who.int/medicinedocs/documents/s17032f/s17032f.pdf lu 10/12/2016

Submit or recommend next manuscript to OALib Journal and we will provide best service for you:

- Publication frequency: Monthly

- 9 subject areas of science, technology and medicine

- Fair and rigorous peer-review system

- Fast publication process

- Article promotion in various social networking sites (LinkedIn, Facebook, Twitter, etc.)

- Maximum dissemination of your research work

Submit Your Paper Online: Click Here to Submit

Or Contact service@oalib.com 